\title{
Sustentabilidade e expansão da agricultura irrigada: um olhar para 0 setor no estado de Goiás
}

O setor do agronegócio possui expressiva representatividade na economia brasileira com a geração de emprego, renda e riqueza, destacando-se, especialmente na composição do Produto Interno Bruto (PIB) de diversas regiões do país. Ao mesmo tempo, a atividade agrícola é um dos setores que mais demanda água, exigindo dos órgãos públicos efetividade nas políticas de gestão dos recursos naturais por serem eles bens comuns. $\mathrm{O}$ objetivo deste trabalho é apresentar um panorama de sustentabilidade da expansão da agricultura irrigada em Goiás. Para atingi-lo, foi realizada uma pesquisa exploratória e descritiva, por meio de análise documental em dados disponibilizados pela SEAGRO acerca do cadastramento dos irrigantes que possibilitou construir um panorama da expansão da irrigação nesse estado, a qual tornou possível discutir o assunto sob a ótica de políticas públicas para regulação do setor, em buscar do aprimoramento de pesquisas científicas que venham a contribuir com a sustentabilidade do setor irrigante no estado de Goiás.

Palavras-chave: Economia Ambiental; Sustentabilidade; Irrigação.

\section{Sustainability and expansion of irrigated agriculture: a look at the sector in the state of Goiás}

The agribusiness sector has significant representation in the Brazilian economy with the generation of employment, income and wealth, especially in the composition of the Gross Domestic Product (GDP) of various regions of the country. At the same time, agricultural activity is one of the sectors that most demands water, requiring public agencies to be effective in natural resource management policies because they are common goods. The objective of this paper is to present a panorama of sustainability of the expansion of irrigated agriculture in Goiás. To reach it, an exploratory and descriptive research was carried out, through documental analysis of data provided by SEAGRO about the registration of irrigants that made it possible to build a panorama of the expansion of irrigation in this state, which made it possible to discuss the subject from the perspective of public policies to regulate the sector, seeking to improve scientific research that will contribute to the sustainability of the irrigating sector in the state of Goiás.

Keywords: Environmental economics; Sustainability; Irrigation.

Topic: Desenvolvimento, Sustentabilidade e Meio Ambiente

Reviewed anonymously in the process of blind peer.
Received: 20/01/2019

Approved: 25/02/2019
Maria Gláucia Dourado Furquim

Instituto Federal Goiano, Brasil

http://lattes.cnpq.br/2681775689273863

maria.furquim@ifgoiano.edu.br

Klaus de Oliveira Abdala (iD

Universidade Federal de Goiás, Brasil

http://lattes.cnpq.br/8041644148923970

http://orcid.org/0000-0002-6466-9905

agroklaus@gmail.com

\section{Referencing this:}

FURQUIM, M. G. D.; ABDALA, K. O.. Sustentabilidade e expansão da agricultura irrigada: um olhar para o setor no estado de Goiás. Natural Resources, v.9, n.1, p.47-56, 2019. DOI: http://doi.org/10.6008/CBPC2237-9290.2019.001.0006 


\section{INTRODUÇÃO}

A irrigação configura o conjunto de técnicas que, por meio do deslocamento da água no tempo e no espaço, possibilitam ajustar os recursos naturais às demandas agrícolas em determinada região. Essa tecnologia remonta-se à história da agricultura no mundo, com evidências de sua prática nas civilizações antigas da Suméria, há 4.000a.C (MAZOYER et al., 2010). Embora seja uma técnica agrícola antiga, o uso da irrigação tornou-se mais comum nos últimos trinta anos, em virtude do aumento populacional, que pressionou a oferta de alimentos, fazendo com que a agricultura irrigada se consolidasse como uma opção estratégica para satisfazer essa demanda.

No Brasil, vários programas governamentais instituíram políticas públicas que vem fomentando a expansão do setor desde a década de 1960. Segundo Christofidis (2005), é possível estimar um crescimento mundial da superfície irrigada de 100 milhões de hectares até 2050. Desse total, 26 milhões de hectares de áreas potencialmente irrigáveis se encontram no Brasil, especialmente favorecido devido a um conjunto de fatores como a extensão territorial, as condições físico-climáticas favoráveis e a disponibilidade hídrica, com destaque para a região Centro-Oeste, a segunda maior em prospecção de área.

Na Região Centro-Oeste, destaca-se o estado de Goiás, onde a adoção de sistemas de irrigação nas atividades agropecuárias tem se expandido significativamente, tornando-o o segundo maior estado em concentração de irrigação no País. Essa expansão pode ser caracterizada tecnológica, geográfica e agronomicamente e, concentrada em sistemas de irrigação, regiões e culturas específicas, impulsiona localmente a economia, fomentando a formação de polos agroindustriais de processamento e beneficiamento de alimentos nas regiões onde o uso da irrigação vai se consolidando.

Entretanto, é preciso considerar que, economicamente, a gestão sustentável de uso da água, por ser um recurso natural renovável, deve buscar o equilíbrio entre sua taxa de recomposição e sua taxa de exploração, de forma a atender os usos consuntivos (água captada do manancial e que a ele não retorna), não consuntivos (a água captada retorna ou permanece no manancial) e a conservação dos ecossistemas (ENRÍQUEZ, 2003). Logo, ao mesmo tempo em que fomenta o agronegócio goiano, esse cenário de expansão da irrigação demanda mais atenção do poder público em se instituir políticas de gestão eficiente dos recursos hídricos, uma vez que estes são considerados bens públicos e, portanto, sujeitos à regulação estatal. Nesse contexto, o artigo pretende apresentar um panorama da expansão da irrigação no estado de Goiás que permita discutir as políticas públicas necessárias à regulação do setor irrigante no estado.

\section{METODOLOGIA}

O Estado de Goiás é considerado um dispersor de águas no Brasil, por possuir em seu território rios que alimentam diversas bacias hidrográficas (MARTINS, et al., 2014). Inserido na região hidrográfica do Tocantins/Araguaia, São Francisco e Paraná, o estado de Goiás possui uma área de $340.111,783 \mathrm{~km}^{2}$, o que corresponde a 3,99\% do território nacional, contemplando 246 municípios com população total em 2010 de 6.003.788 habitantes distribuídos $90,29 \%$ na zona urbana e $9,71 \%$ na zona rural. O estado possui uma 
precipitação média anual de $1.564 \mathrm{~mm}, 197 \mathrm{~mm}$ abaixo da média nacional, e seu balanço hídrico em termos quali-quantitativo apresenta situação satisfatória (ANA, 2013).

Regionalmente, o setor agropecuário é de extrema representatividade para a economia goiana, tendo em 2011 correspondido diretamente a 12,5\% do PIB estadual com ampliação para 14,1\% nos anos subsequentes, e indiretamente o setor fornece matéria-prima para as indústrias de produtos alimentícios. Realizou-se uma abordagem exploratória e descritiva, com a identificação e a análise dos aspectos relacionados ao fenômeno estudado (LAKATOS et al., 2001).

Assim, por meio de revisão de literatura e da pesquisa documental em dados disponibilizados pela Secretaria de Desenvolvimento do Estado de Goiás (SEAGRO, 2014), referentes ao cadastramento dos irrigantes desse estado - uma amostra de 2.544 produtores, o que corresponde a 48,32\% da população de irrigantes cadastrados, no período de 2012 à abril de 2014 e à 52\% do número de projetos estimados no Estado - foi possível apresentar e discutir aspectos específicos à sustentabilidade da expansão da irrigação no local.

\section{RESULTADO E DISCUSSÃO}

A expansão da irrigação no Brasil pode ser associada a um conjunto de políticas públicas de fomento ao setor. Segundo a Agência Nacional das Águas (ANA, 2014), a intervenção pública, por meio da instituição de programas de irrigação, buscou, desde a década de 1960, fomentar a economia regional pela geração de emprego e renda e consequente redução da pobreza, especialmente na região semiárida do nordeste e do norte de Minas Gerais.

Esses programas foram intensificados e difundidos pelo território nacional ao longo da década de 1980, com o Programa Nacional para Aproveitamento Racional de Várzeas Irrigáveis (PROVÁRZEAS), em 1981; o Programa de Financiamento de Equipamentos de Irrigação (PROFIR), em 1982; o Programa Nacional de Irrigação (PRONI), em 1986; e o Programa de Irrigação do Nordeste (PROINE), em 1986 (BERNARDES, 1998).

Segundo Testezlaf et al. (2002), as ações provenientes de políticas em favor da irrigação foram voltadas ao desenvolvimento regional, associadas à implantação de programas especiais por parte dos governos federais e estaduais. Esses programas foram quase sempre estabelecidos em épocas específicas e, portanto, com forte conotação conjuntural e atendendo demandas regionais bem definidas.

Apesar do propósito difusor da tecnologia, a década de 1980 caracterizou-se pelas obras de irrigação de uso comum, pela infraestrutura elétrica e pelo apoio financeiro, realizados pelo governo federal. Essas ações promoveram a concentração da irrigação em regiões específicas e que, atualmente, em virtude da vazão demandada, têm gerado conflitos no setor agropecuário e entre os demais setores da economia local (BRASIL, 2008).

No que diz respeito à distribuição espacial da irrigação, quatro estados brasileiros concentram $80 \%$ da área irrigada do País, sendo eles Minas Gerais (31,9\%), Goiás (18,3\%), Bahia $(15,8 \%)$ e São Paulo $(14,1 \%)$ (LANDAU et al., 2014). Nesses estados, os métodos de irrigação mais utilizados são: sistema tipo pivô central 
(38\%); localizado (31,4\%); e por aspersão (30,4\%) (IBGE, 2006). De acordo com dados disponibilizados pela SEAGRO (2014), referentes ao cadastramento dos irrigantes no estado de Goiás entre o período de 1978 e 2014, 62\% dos sistemas cadastrados foram tipo pivô central, o que corresponde a aproximadamente $85 \%$ da área irrigada no estado (tabela 1).

Tabela 1: Sistemas de irrigação cadastrados no estado de Goiás até abril de 2014.

\begin{tabular}{|l|l|l|l|}
\hline Sistemas de Irrigação & Quantidade & Área (hectares) & Percentual (\%) \\
\hline Pivô Central & 1587 & $100.627,44$ & 62,38 \\
\hline Convencional Semiportátil & & & \\
& 230 & 819,78 & 9,04 \\
\hline Localizada - Gotejamento & 188 & $2.344,45$ & 7,39 \\
\hline Localizada - Microaspersão & & & \\
& 148 & $1.826,00$ & 5,82 \\
\hline Convencional fixa & 129 & 585,05 & 5,07 \\
\hline Sulco & 94 & 208,79 & 3,69 \\
\hline Inundação & 74 & $11.011,60$ & 2,91 \\
\hline Convencional portátil & 61 & 249,68 & 2,40 \\
\hline Autopropelido & 29 & 503,59 & 1,14 \\
\hline Corrugação & 4 & 9,30 & 0,16 \\
\hline Total & $\mathbf{2 5 4 4}$ & $\mathbf{1 1 8 . 1 8 5 , 6 8}$ & $\mathbf{1 0 0}$ \\
\hline
\end{tabular}

Fonte: SEAGRO (2014).

Verificada também a demanda de área irrigada no estado, foi apurada uma área total de 51.122,21 hectares, dos quais $43.968,40$ hectares, ou seja, $86 \%$, são para implantação de sistema pivô central, o que indica a continuidade desse padrão de distribuição tecnológica entre os diferentes sistemas de irrigação. Segundo Testezlaf (2017), o sistema de irrigação tipo pivô central, devido à capacidade da tubulação de fletir entre as torres e a possibilidade de controle da lâmina d'água por meio de válvulas eletrônicas, permitiu a automação de todo o processo de irrigação e sua adaptação a terrenos ondulados, reduzindo a demanda por mão-de-obra na operação do sistema. Tais atributos promoveram a rápida aceitação dessa tecnologia no mercado, tornando-o um dos sistemas de irrigação mais difundidos globalmente.

Apesar das vantagens do sistema de irrigação via pivô central, que o tornaram popular e fomentaram sua difusão, o uso das técnicas de irrigação atuam diretamente sobre os recursos naturais (água, solo, flora e fauna) e os impactos gerados podem ter consequências tanto ambientais como socioeconômicas quando esses sistemas são utilizados sem respeitar os princípios de sustentabilidade (TESTEZLAF, 2017).

Conforme Schmidt (2007), a incorporação do uso da irrigação pode estar relacionada aos impactos ambientais a montante, no perímetro irrigado, e à jusante da área. Dentre os principais impactos à montante, identificam-se impactos em: sistemas de barramento, canais de derivação, linhas de transmissão de energia, volume de água captada, entre outros. No perímetro irrigado, os principais efeitos são correlacionados ao escorrimento superficial, à degradação do solo, à quimigação, à salinização e à lixiviação, que ocorrem em função do material geológico do solo e/ou do acúmulo de produtos químicos, com potenciais impactos à jusante, sobretudo relacionados à quantidade e à qualidade da água.

Testezlaf (2017) relata, ainda, como principais desvantagens do sistema tipo pivô central, as perdas por ineficiências técnicas, operacionais e econômicas, especificamente relacionadas: ao estado de 
conservação/manutenção dos equipamentos; às condições ambientais de aplicação da irrigação; e à seleção de culturas irrigadas, uma vez que o sistema apresenta alto custo de implantação.

Ao se considerar que $87 \%$ dos equipamentos que usam a tecnologia pivô central no estado de Goiás apresentam tempo de uso de 20 anos ou mais (tabela 2), esse cenário de impactos se torna potencialmente grave, uma vez que a depreciação física ou obsolescência tecnológica interfere em sua eficiência (CATTY, 2013), aumentando as perdas e, logo, o volume de captação, a escassez hídrica, a possibilidade de contaminação dos solos e do ecossistema, pela quimigação e geração de conflitos sociais a partir do uso excessivo do recurso hídrico.

Tabela 2: Número de equipamentos de irrigação com mais de 20 anos de uso no estado de Goiás.

\begin{tabular}{|l|l|l|}
\hline Sistemas de irrigação & Quantidade & Percentual (\%) \\
\hline Pivô Central & 408 & 86,81 \\
\hline Convencional Semiportátil & 16 & 3,40 \\
\hline Localizada - Gotejamento & 10 & 2,13 \\
\hline Localizada - Microaspersão & 6 & 1,28 \\
\hline Convencional fixa & 14 & 2,98 \\
\hline Convencional portátil & 8 & 1,70 \\
\hline Autopropelido & 8 & 1,70 \\
\hline Total & $\mathbf{4 7 0}$ & $\mathbf{1 0 0}$ \\
\hline
\end{tabular}

Fonte: SEAGRO (2014).

A eminente exaustão dos recursos hídricos tem exigido que os órgãos de regulamentação e fiscalização do uso da água tenham mais rigor a título de assegurar a sustentabilidade das atividades. Todavia, o cumprimento da legislação específica tem esbarrado em algumas barreiras institucionais, tais como: burocracia, morosidade, custos de transação elevados e falta de conscientização.

Esse entrave institucional pode ser evidenciado ao se observar o índice de adesão aos processos de outorga de uso da água para irrigação (tabela 3), uma vez que, dos 2.544 irrigantes cadastrados, apenas 1.341 , ou 53\%, possuem outorga para o uso da água. Considerando que a outorga atualmente é o principal instrumento de regulação e controle do uso do recurso hídrico no estado, fica evidente a possibilidade de conflitos regionais, ou locais, decorrentes do uso excessivo desse recurso.

Tabela 3: Número de irrigantes $x$ outorga de uso da água no estado de Goiás.

\begin{tabular}{|l|l|l|}
\hline Possui outorga de uso & Quantidade & Percentual (\%) \\
\hline Sim & 1.341 & 52,71 \\
\hline Não & 886 & 34,83 \\
\hline Em andamento & 170 & 6,68 \\
\hline Tato responderam & 147 & 5,78 \\
\hline
\end{tabular}

Fonte: SEAGRO (2014).

Fato igualmente relevante ao argumento de ineficiência no uso do equipamento, refere-se ao manejo do sistema de irrigação, o que compreende a determinação precisa da quantidade de água e das condições climáticas durante a aplicação, conforme demanda da cultura, segundo seus estágios fisiológicos e suas características edáficas (TESTEZLAF, 2017).

Nesse contexto, segundo dados da pesquisa (SEAGRO, 2014), do total de 2.544 irrigantes cadastrados, 1.118 não realizam manejo de água, enquanto 296 preferiram não responder. Esse fato 
representa a possibilidade de impactos na oferta do recurso hídrico devido à sua utilização, bem como aqueles relacionados à contaminação ambiental, por defensivos agrícolas carreados pelos fluxos hídricos infiltrantes e/ou escoados superficialmente.

O local de captação de água pelos sistemas pivô central constitui, também, fonte de impactos relacionados a essa tecnologia. Segundo a SEAGRO (2014), dos 1.587 irrigantes usuários da tecnologia pivô central, 1.217 utilizam o barramento (tabela 4). Esses barramentos são considerados um impacto a montante do projeto, tanto pela alteração do ecossistema, quando de sua construção, quanto pelo risco de rompimento, com a consequente perda de serviços ecológicos decorrente dessas alterações. Todavia, eles contribuem para a regularização da vazante nos rios por favorecer, pelo processo de infiltração no subsolo, a nutrição dos aquíferos.

Tabela 4: Número de equipamentos $x$ local de captação de água com pivô central no estado de Goiás.

\begin{tabular}{|l|l|l|}
\hline Locais de captação & Quantidade & Percentual \\
\hline Com barramento & 1.217 & 76,69 \\
\hline Sem barramento & 350 & 22,05 \\
\hline Lago natural & 5 & 0,32 \\
\hline Poço profundo & 8 & 0,50 \\
\hline Poço raso & 5 & 0,32 \\
\hline Desvio com tanque & 2 & 0,13 \\
\hline Total & $\mathbf{1 . 5 8 7}$ & $\mathbf{1 0 0}$ \\
\hline
\end{tabular}

Fonte: SEAGRO (2014).

Quanto à distribuição dos usuários por bacia e microbacia,130 estão presentes na Bacia do Rio Araguaia, 191 usuários na do Rio São Francisco, 578 na do Rio Tocantins e 1.720 na do Rio Paranaíba. Destes 1.720, a distribuição se faz da seguinte forma: a maior concentração está na microbacia do Rio São Marcos, com 535 usuários, 429 no Rio Corumbá, 364 no Rio dos Bois e 299 no Rio Meia Ponte.

Essa distribuição irregular, centralizada na região do entorno do Distrito Federal e na região sul do estado, acarreta elevado uso da água em bacias específicas, podendo ocasionar comprometimento hídrico e conflitos socioeconômicos. Verificou-se também a demanda de área irrigada reprimida no Estado, sendo apurada uma área total de 51.122,21ha, destes, 43.968,40ha, ou seja, 86\% são para implantação de sistema de pivô central. Quanto aos 10 municípios que mais irrigam no estado de Goiás, considerando apenas áreas irrigadas por pivô central, as informações do ranking divulgado pelo IBM diferem dos resultados aferidos pelo cadastramento da SED.

Tabela 5: Demanda de área irrigada reprimida no estado de Goiás.

\begin{tabular}{|l|c|c|}
\hline \multicolumn{1}{|c|}{ Sistemas de Irrigação } & Área Irrigada Reprimida (ha) & Percentual \\
\hline Pivô Central & $43.968,40$ & 86,01 \\
\hline Convencional Semiportátil & 66,98 & 0,13 \\
\hline Localizada - Gotejamento & 491,02 & 0,96 \\
\hline Localizada - Microaspersão & 425,50 & 0,83 \\
\hline Convencional Fixa & 224,36 & 0,44 \\
\hline Sulco & 96,75 & 0,19 \\
\hline Inundação & $4.990,00$ & 9,76 \\
\hline Convencional Portátil & 119,34 & 0,23 \\
\hline Corrugação Total & 1,50 & 0,00 \\
\hline Autopropelido & 738,36 & 1,44 \\
\hline \multicolumn{1}{|c|}{$51.122,21$} & 100 \\
\hline
\end{tabular}

Fonte: SEAGRO (2014). 
Tabela 6: Estado de Goiás: Ranking dos 10 municípios com maior área irrigada por pivôs.

\begin{tabular}{|l|l|}
\hline \multicolumn{1}{|c|}{ Municípios } & \multicolumn{1}{c|}{ Municípios } \\
\hline Água Fria de Goiás & Campo Alegre de Goiás \\
\hline Campo Alegre de Goiás & Cristalina \\
\hline Catalão & Ipameri \\
\hline Cristalina & Jussara \\
\hline Ipameri & Luziânia \\
\hline Jussara & Morrinhos \\
\hline Luziânia & Palmeiras de Goiás \\
\hline Morrinhos & Paraúna \\
\hline Paraúna & Rio Verde \\
\hline Rio Verde & Vianópolis \\
\hline
\end{tabular}

Além dos impactos ecológicos, os dados da pesquisa aqui referenciada permitem também evidenciar aspectos relevantes aos impactos econômicos do uso dos sistemas de irrigação. A água, quando utilizada por meio de infraestrutura hídrica de captação, consiste em fator de produção que compõe o sistema de produção agrícola, assim como sementes, máquinas e implementos, mão-de-obra, fertilizantes e defensivos agrícolas. Nesse sentido, ao contrário da agricultura de sequeiro, a agricultura irrigada normalmente contempla o recurso água como insumo a ser utilizado eficientemente, a fim de se obter elevado índice de produtividade e, consequentemente, mais retorno econômico.

O conceito de produtividade da água (WP), abordado por Kijine et al. (2003), descrito como a capacidade do sistema agrícola de produção de transformar água em alimentos e fazê-lo eficientemente, representa um indicador de desempenho econômico que considera os elementos básicos de um sistema de irrigação, expressos como a proporção da saída de produtos para cada unidade de entrada de fator (água que consome), ou seja, o componente água é apresentado, na irrigação, em um contexto econômico, constituindo um dos parâmetros (fator) de uma função de produção.

Dessa forma, os recursos hídricos, enquanto fator de produção, acarretam custos, mesmo que seu preço não esteja explícito. Ainda que na maioria das regiões do País não exista a cobrança pelo uso da água de irrigação, o valor econômico desse recurso se expressa no gasto com energia para realizar o bombeamento, no investimento para aquisição de equipamento para levar a água do manancial à lavoura e, especialmente, no custo social de oportunidade, por ser ela um bem público (ALBUQUERQUE, 2004).

Cook et al. (2006) apresenta, a partir do conceito de produtividade da água (KIJINE et al., 2003), diferentes parâmetros para estimar esse indicador. Segundo Cook et al. (2006), no âmbito privado, o uso de sistemas com elevado custo de implantação deveria ser planejado para produzir culturas que agregassem mais valor, bruto ou líquido, ao recurso utilizado. Já na dimensão social, deveriam estar contabilizados os custos de oportunidade do uso do recurso hídrico e, entre eles, a possibilidade de aumento de oferta e a consequente redução de preços pagos ao consumidor de culturas de maior valor de mercado.

Nesse contexto, analisando as culturas irrigadas mais produzidas, de acordo com o cadastramento (SEAGRO, 2014) - algodão, alho, batata, beterraba, cabotiá, café, cebola, cenoura, cevada, feijão, kinoa, linhaça, milho, milho doce, milho pamonha, milho semente, pastagem, soja, tomate e trigo -é possível inferir uma diversificação de culturas sugerida pelo próprio cadastro. Entretanto, Abdala (2012), analisando o uso do solo por sistemas de irrigação tipo pivô central no estado de Goiás, concluiu que, dos 26 municípios que 
usavam essa tecnologia, 16 deles estariam utilizando mais de 50\% desse sistema para produzir culturas com reduzida renda bruta da terra, tais como milho, pastagem e soja, o que seria indicativo de ineficiência econômica do uso da água.

Do exposto ao longo deste artigo, é possível concluir que a expansão da irrigação no estado de Goiás tem sido um processo contraditório, segundo o qual programas de desenvolvimento do setor instituíram políticas visando a difusão tecnológica necessária ao aumento da produtividade da terra, da oferta de alimentos e do desenvolvimento regional, fomentando a formação de polos agroindustriais de processamento e beneficiamento de alimentos nas regiões onde o uso da irrigação vai se consolidando.

Entretanto, é possível evidenciar distorções à efetividade dessas políticas. Concentrada em sistemas de irrigação, regiões e culturas específicas, essa expansão manifesta uma série de impactos, que podem ser relacionados aos recursos hídricos demandados pela tecnologia. Assim, o uso ineficiente da tecnologia de irrigação cria condições de escassez física (demanda de consumo maior do que a oferta do recurso) ou bioquímica (contaminação, tornando o recurso impróprio para usos específicos) do recurso, com consequências ambientais e socioeconômicas negativas, o que pode, em uma análise custo-benefício, evidenciar custo-efetividade negativo ou ineficiência alocativa do recurso hídrico (THOMAS et al., 2010).

Apesar da existência do instrumento de gestão pública do recurso hídrico, instituído por meio da política de outorga e licenciamento ambiental, verificou-se, ao longo deste trabalho, baixa adesão a ele, bem como a sua ineficácia em garantir que o recurso hídrico tenha destinação social mais efetiva, uma vez constatado o uso do recurso para produção de culturas de baixo valor comercial.

A sustentabilidade do uso da água pode ser alcançada por ações que limitam a quantidade utilizada por unidade de qualquer atividade, favorecendo a conservação dos corpos hídricos. Portanto, para que haja eficiência intertemporal, torna-se necessário adotar estratégias de manejo que reduzam as perdas que acontecem nos reservatórios, na condução e na aplicação de água nas áreas irrigadas, bem como aprimorar os métodos de irrigação e de manutenção em equipamentos. Com a instituição da Política Nacional de Recursos Hídricos, a água passou a ser caracterizada como bem econômico, sendo passível de cobrança o direito à sua utilização.

Assim, cobrança pelo uso dos recursos hídricos pode ser considerada um dos mais eficazes indutores do uso racional desse recurso, com vistas a influenciar na decisão da localização espacial da atividade econômica, redistribuir os custos sociais e incorporar as dimensões social e ambiental ao planejamento global, além de promover a formação de fundos para projetos, intervenções, obras e outros trabalhos do setor.

Entretanto, a eficácia desse instrumento em alcançar esses objetivos depende do valor unitário a ser cobrado pelo recurso hídrico e da forma de implantação desse mecanismo. Nesse sentido, Finkler et al. (2015) esclarece que a iniciativa nacional de implantação desse instrumento tem se baseado em modelos de ampliação da oferta do recurso e se fundamentado na formação de fundos para projetos, intervenções, obras e outros trabalhos do setor. 
Portanto, a pesquisa científica tem um vasto território a ser explorado no sentido de valoração do recurso hídrico, para fins de análise de sua eficiência alocativa e simulação de cenários de impacto em indicadores socioeconômicos locais, tendo como produto desses trabalhos a proposta de valores de cobrança pelo uso do recurso hídrico.

\section{CONSIDERAÇÕES FINAIS}

A agricultura irrigada permite mais domínio humano sobre aspectos naturais, como secas ou estiagem prolongadas, proporcionando mais autonomia sobre o processo produtivo por meio da redução de riscos de clima e mercado. Todavia, a maior produtividade é consequência, necessariamente, da combinação ótima dos insumos empregados na produção, inclusive do fator água. A gestão inadequada do sistema pode acarretar uma série de externalidades ambientais negativas no processo, como a poluição ou depauperamento dos recursos hídricos, com alterações no ciclo hidrológico fluvial; deterioração dos solos; dentre outras.

Considerando o fato de que a água é um recurso com disponibilidade cada vez mais limitada em quantidade e qualidade e de utilidade múltipla, a sustentabilidade em seu uso torna-se fator condicionante na promoção do desenvolvimento econômico e do bem-estar social. Dessa forma, realizar o mapeamento dos irrigantes e de suas práticas de gestão dos sistemas de irrigação possibilita a assertiva tomada de decisão a partir das potencialidades e restrições evidenciadas em cada região.

O potencial agrícola e de irrigação no Brasil carece de internalizar, por parte dos agropecuaristas, a percepção da representatividade do meio ambiente e dos serviços por ele prestados para promover um setor agropecuário sustentável. Nesse sentido, a adoção da prática da agricultura irrigada contribui para a redução da extração da cobertura vegetal nativa para a expansão agrícola, por apresentar vantagens no aumento da produtividade decorrente do uso intensivo do solo. Todavia, para o desenvolvimento da agricultura irrigada sustentável é imperativo considerar a aptidão do solo, o cumprimento às exigências da legislação ambiental e, especialmente, a disponibilidade de recursos hídricos sem risco de conflitos com outros usos prioritários da água.

Os recursos naturais do planeta são fruto de ciclos naturais da Terra e a forma de recomposição em relação à ação do homem em um contexto de tempo estabelece os critérios para classificá-los como recursos renováveis e não renováveis. A água, assim como os solos, o ar, a fauna e a flora, é considerada recurso natural renovável, pois seus ciclos de reconstituição são compatibilizados com o tempo de vida do homem.

Entretanto, em função do uso e do consumo exacerbados, pode ocorrer o esgotamento desses recursos, comprometendo a sobrevivência da espécie humana e dos diversos ecossistemas, demandando do poder público a regulamentação do uso dos recursos hídricos por meio de uma gestão planejada e eficiente destes. Emerge, portanto, a necessidade de alinhar o atual modelo produtivo dos diversos setores da economia as práticas sustentáveis de conservação e preservação do meio ambiente, a título de assegurar a disponibilidade desses recursos naturais e insumos produtivos para a atual e futuras gerações. 


\section{REFERÊNCIAS}

ABDALA, K. O.. Dinâmica de competição agropecuária pelo uso do solo no estado de Goiás e implicações para a sustentabilidade dos recursos hídricos e remanescentes florestais. Tese (Doutorado) - Universidade Federal de Goiás, Goiânia, 2012.

ALBUQUERQUE, P. E. P.. Aspectos conceituais do uso eficiente da água na agricultura. In: SIMPÓSIO NACIONAL SOBRE O USO DA ÁGUA NA AGRICULTURA. Anais. Passo Fundo: 2004.

ANA. Agência Nacional de Águas. Cobrança pelo uso de recursos hídricos. Brasília: ANA, 2014.

BERNARDES, L.. Papel do governo e da iniciativa privada no desenvolvimento da agricultura irrigada no Brasil. In: SEMINÁRIO INTERNACIONAL DE POLÍTICAS DE IRRIGAÇÃO E DRENAGEM. Anais. Brasília: MMA, 1998.

BRASIL. Ministério da Integração Nacional. A irrigação no Brasil: situação e diretrizes. Brasília: MIN, 2008.

CATTY, J.. IFRS: guia de aplicação do valor justo. Porto Alegre: Bookman, 2013.

CHRISTOFIDIS, D.. Água e agricultura. Brasília: MIN, 2005.

COOK, S. E.; TURRAL, H.; GICHUKI, F.. Agricultural water productivity: issues, concepts and approaches. Basin Focal Project Working Paper, n.1, p.17, 2006.

ENRÍQUEZ, M. A. R. S.. Economia dos recursos naturais. In: MAY, P. H.; LUSTOSA, M. C.; VINHA, V.. Economia do meio ambiente: Teoria e Prática. Rio de Janeiro: Elsevier, 2003.

FINKLER, N. R.; MENDES, L. A.; BORTOLIN, T. A.. Cobrança pelo uso da água no Brasil: uma revisão metodológica. Desenvolvimento e Meio Ambiente, v.33, p.33-49, 2015.
IBGE. Instituto Brasileiro de Geografia e Estatística. Censo Agropecuário de 2006. Rio de Janeiro: IBGE, 2006.

KIJINE, J. W.; BARKER, R.; MOLDEN, D.. Improvement water productivity in agriculture: editors' overview. In: KIJINE, J. W.. Water productivity in agriculture: limits and opportunities for improvement. Colombo: CABI, 2003. p.1119.

LAKATOS, E. M.; MARCONI, M. A.. Fundamentos de metodologia científica. 4 ed. São Paulo: Atlas, 2001.

MAZOYER, M.; ROUDART, L.. 1933: História das agriculturas no mundo: do neolítico à crise contemporânea. São Paulo: EDUNESP, 2010.

SCHMIDT, W.. Agricultura irrigada e o licenciamento ambiental. Tese (Doutorado) - Escola Superior de Agricultura Luiz de Queiroz, Piracicaba, 2007.

SEAGRO. Secretaria de Estado da Agricultura, Pecuária e Irrigação. Cadastramento dos irrigantes no Estado de Goiás: Dados obtidos durante a pesquisa junto à atual SED. Goiânia: SEAGRO, 2014.

TESTEZLAF, R.. Irrigação: métodos, sistemas e aplicações. Campinas: UNICAMP, 2017.

TESTEZLAF, R.; MATSURA, E. E.; CARDOSO, J. L.. Importância da irrigação no desenvolvimento do Agronegócio. Campinas: UNICAMP, 2002.

THOMAS, J. M.; CALLAN, S. J.. Economia ambiental: fundamentos, políticas e aplicações. São Paulo: Cengage Learning, 2010.

A CBPC - Companhia Brasileira de Produção Científica (CNPJ: 11.221.422/0001-03) detém os direitos materiais desta publicação. Os direitos referem-se à publicação do trabalho em qualquer parte do mundo, incluindo os direitos às renovações, expansões e disseminações da contribuição, bem como outros direitos subsidiários. Todos os trabalhos publicados eletronicamente poderão posteriormente ser publicados em coletâneas impressas sob coordenação da Sustenere Publishing, da Companhia Brasileira de Produção Científica e seus parceiros autorizados. Os (as) autores (as) preservam os direitos autorais, mas não têm permissão para a publicação da contribuição em outro meio, impresso ou digital, em português ou em tradução. 